Article

\title{
Combined Vapor Permeation and Continuous Solid-State Distillation for Energy-Efficient Bioethanol Production
}

\author{
Hongshen Li ${ }^{1,2}$, Hongrui Liu ${ }^{1,2}$, Yufang $\mathrm{Li}^{3}$, Jilin Nan ${ }^{3}$, Chen Shi ${ }^{3}$ and Shizhong $\mathrm{Li}^{1,2, *}$ \\ 1 Institute of New Energy Technology, Tsinghua University, Beijing 100084, China; \\ lihs83@mail.tsinghua.edu.cn (H.L.); hongruiliu@mail.tsinghua.edu.cn (H.L.) \\ 2 Beijing Engineering Research Center for Biofuels, Beijing 100084, China \\ 3 Ningbo Sinyuan Membrane Industry Incorporated Company, Ningbo 315021, China; \\ yf.li@sinyuan.com (Y.L.); jl.nan@sinyuan.com (J.N.); c.shi@sinyuan.com (C.S.) \\ * Correspondence: szli@mail.tsinghua.edu.cn; Tel.: +86-010-62772123
}

Citation: Li, H.; Liu, H.; Li, Y.; Nan, J.; Shi, C.; Li, S. Combined Vapor

Permeation and Continuous

Solid-State Distillation for

Energy-Efficient Bioethanol

Production. Energies 2021, 14, 2266.

https://doi.org/10.3390/en14082266

Academic Editor: Luísa

Seuanes Serafim

Received: 17 March 2021

Accepted: 14 April 2021

Published: 17 April 2021

Publisher's Note: MDPI stays neutral with regard to jurisdictional claims in published maps and institutional affiliations.

Copyright: (c) 2021 by the authors. Licensee MDPI, Basel, Switzerland. This article is an open access article distributed under the terms and conditions of the Creative Commons Attribution (CC BY) license (https:// creativecommons.org/licenses/by/ $4.0 /)$.

\begin{abstract}
Extracting ethanol by steam directly from fermented solid-state bagasse is an emerging technology of energy-efficient bioethanol production. With continuous solid-state distillation (CSSD) approach, the vapor with more than $25 \mathrm{wt} \%$ ethanol flows out of the column. Conventionally, the vapor was concentrated to azeotrope by rectification column, which contributes most of the energy consumption in ethanol production. As an alternative, a process integrating CSSD and vapor permeation (VP) membrane separation was tested. In light of existing industrial application of $\mathrm{NaA}$ zeolite hydrophilic membrane for dehydration, the prospect of replacing rectification operation with hydrophobic membrane for ethanol enriching was mainly analyzed in this paper. The separation performance of a commercial PDMS/PVDF membrane in a wide range of ethanol-water-vapor binary mixture was evaluated in the experiment. The correlation of the separation factor and permeate flux at different transmembrane driving force was measured. The mass and energy flow sheet of proposed VP case and rectification case were estimated respectively with process simulation software based on experimental data. Techno-economic analysis on both cases was performed. The results demonstrated that the additional VP membrane cost was higher than the rectification column, but a lower utilities cost was required for VP. The discount payback period of supplementary cost for VP case was determined as 1.81 years compared with the membrane service lifetime of 3 years, indicating that the hybrid CSSD-VP process was more cost effective and energy efficient.
\end{abstract}

Keywords: bioethanol; vapor permeation; continuous solid-state distillation; PDMS/PVDF membrane; rectification; technoeconomic evaluation

\section{Introduction}

Replacing fossil fuels with bio-origin fuels can provide a feasible solution to reduce greenhouse gas emissions and achieve "zero carbon emissions" globally. The alternatives being widely considered are bioethanol and biodiesel in the transportation sector [1]. Bioethanol is fermented from sugars or starches, and biodiesel is produced by the chemical reaction of triglycerides contained in biomass oils or fats [2,3]. With the development of a new generation of green diesel, a larger range of feedstock such as microalgal, waste cooking oils, and municipal sewage sludge can be used to produce diesel in comparison to bioethanol [4-7]. However, the second-generation cellulosic ethanol has encountered a bottleneck due to the high cost of pretreatment and enzymes; therefore, crops such as corn, sugar cane, and sweet sorghum are still the main feedstock for ethanol production [8-10]. Because there is no advantage in raw material cost for bioethanol compared with biodiesel, reducing the energy consumption cost in the production process has become an important element for bioethanol development.

Therefore, energy-efficient bioethanol production technologies attracted considerable attention [11-13]. In the conventional process of bioethanol production, the recovery of 
ethanol from fermentation broth is accomplished by a rectification column which yields an ethanol-water azeotrope of $95.4 \mathrm{wt} \%$ ethanol. Extractive distillation is commonly utilized to remove water from azeotrope to less than $0.5 \mathrm{wt} \%$ to meet the fuel ethanol specification [14]. Energy consumption on rectification and dehydration contributes to the majority of costs and greenhouse emissions of bioethanol production, which accounted for $49 \%$ of the separation energy for liquid fermentation process and $58 \%$ for the solid-state fermentation process $[15,16]$. Thus, reducing energy in enriching ethanol parts to make bioethanol more sustainable and competitive with fossil fuel would be of great interest.

Membrane separation such as vapor permeation (VP) can be less energy intensive than rectification-based processes [17]. VP is achieved by degrees to which components are dissolved and diffused through the dense membrane. It has the advantages over other membrane separation such as pervaporation in that the feed is vapor not liquid [18]. There is no phase transition on either membrane side, meaning it does not need additional energy to supplement the latent heat of vaporization [19]. Vapor feeding also avoids the fouling of fermentation broth, and the operational flexibility is larger [20].

VP is widely studied and commercially applied in industrial-scale ethanol biofuel production for dehydration from ethanol-water azeotrope using hydrophilic membranes for 30 years [21]. The membrane materials have developed from organic materials such as polyvinyl alcohol to inorganic NaA zeolite membrane [22-24]. With the decrease in cost and the improvement of stability, the hollow-fiber membrane devices have been fitted in with 10,000 tons per year bioethanol production scale [25].

In the aspect of ethanol-selective membrane, the current paper mainly focuses on fermentation combined with in situ bioethanol recovery to overcome the ethanol inhibition by continuous removal of it from broth with VP [26,27]. However, few studies attempt to substitute rectification with VP to extract ethanol from fermentation biomass directly. The limitation lies in the fact that producing fuel-grade ethanol from dilute fermentation broth requires high membrane performance. Investment on membrane and equipment could exceed the benefits of energy savings [28,29]. The steam required by the phase transition on fermentation broth reduces the energy efficiency. Gaykawad et al. [30] proposed a flowsheet for ethanol recovery from liquid fermentation off-gas by VP using hydrophobic membrane. Technoeconomic evaluation indicated that the cost of VP process was higher than conventional absorption process because the profit of off-gas recovery was limited.

Vane et al. [31-33] have conducted a series of researches on energy-efficient alternatives to rectification for ethanol recovery from fermentation broth. A hybrid vapor-stripping-VP process was assessed for separating ethanol-water mixture. Aqueous alcohol containing $5 \%$ ethanol was fed into a vapor-stripping column or dephlegmator to $65 \%$ before VP. However, vapor stripping or dephlegmation is not a necessary in liquid fermentation. With the development of advanced solid-state fermentation (ASSF) technology for ethanol biofuel production, it became feasible to use VP instead of rectification on a large scale [34,35]. ASSF can convert from sacchariferous biomass directly into ethanol on solid medium without juice-squeezing energy and water input. Previously, we presented a continuous solid-state distillation (CSSD) process to extract ethanol from fermented biomass [36,37]. The CSSD column was similar to stripping section of a packed column with counter-current mass transfer, but it is a necessary step for ethanol extracting in solid-state process. The CSSD column produces a stable ethanol concentration vapor overhead, which was much more suitable for the VP process. The VP retentate stream could be recycled as secondary heat resource for CSSD column, further reducing the energy consumption.

The objective of this study is to explore an energy-efficient alternative to rectification with VP using ethanol-selective membrane for solid-state bioethanol production. The separation performance of ethanol-water binary mixture vapor permeated through PDMS/PVDF composite membrane can be analyzed. The comparison between the proposed VP case and conventional rectification case on mass flow and energy consumption could be conducted by simulation software. A technoeconomic evaluation of the process 
based on simulation results may predict the industrial application prospect of hybrid CSSD-VP process.

\section{Materials and Methods}

\subsection{Materials}

PDMS/PVDF hydrophobic composite membrane was synthesized by Jiusi High-tech Co. Ltd. (Nanjing, China). This kind of membrane has been commercially applied in the wastewater or VOCs with low ethanol concentration recovery [38]. The PDMS selective layer with the thickness of $10 \mu \mathrm{m}$ was crosslinked with PVDF base layer at $120^{\circ} \mathrm{C}$. The whole thickness of the composite membrane was about $60 \mu \mathrm{m}$. The surface and sectional SEM images of the membrane are shown in Figure 1.

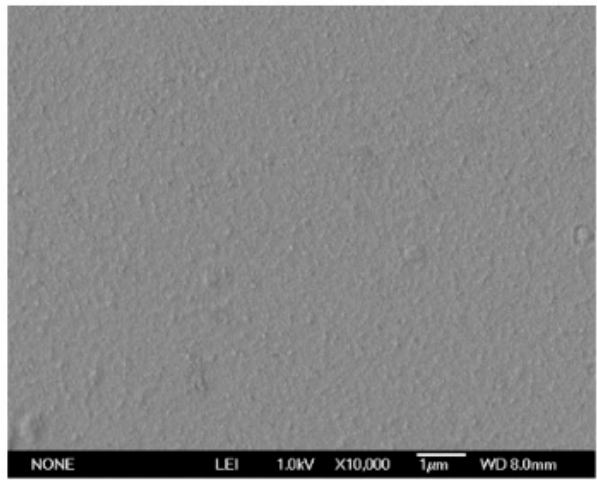

(a)

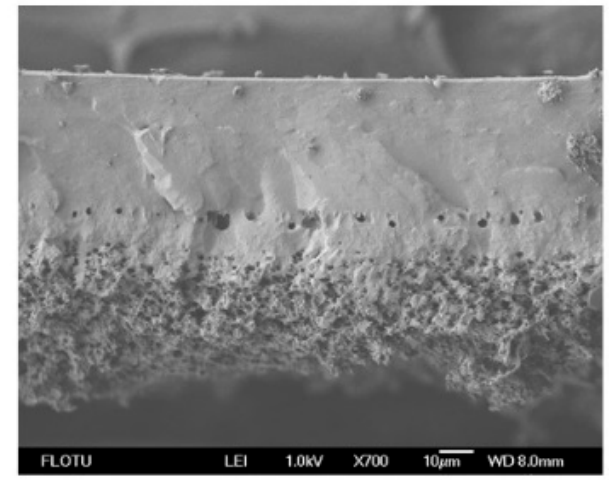

(b)

Figure 1. SEM images of composite PDMS/PVDF membrane: (a) Surface; (b) Sectional.

The ready-made membrane was cut into four squares with a length of $250 \mathrm{~mm}$ and thermopressed on the nonwoven fabric. A flat-sheet membrane module that was composed of two stainless-steel covers and four inner brackets was employed in the experiment. The inner graphite sealing gasket separated the module into four parallel independent chambers with the total effective surface area of $0.2 \mathrm{~m}^{2}$. Absolute ethanol reagent purchased from Tongguang Chemical Co. Ltd. (Beijing, China) was analytical grade and was used without further purification.

\subsection{Experiment Apparatuses and Operation}

Figure 2 displays a schematic diagram of the VP apparatus. A $9 \mathrm{~kW}$ steam generator provided steam with a rated capacity of $12 \mathrm{~kg} / \mathrm{h}$. The steam was divided into two streams. One stream flowed into an isothermal jacket of ethanol evaporator. Absolute ethanol was bubbled in an evaporator and blended with a second steam stream to produce mixture vapor. The compositions and flow rates of the vapor were controlled by adjusting the flow rates of two steam streams using mass flow controllers (MFC). The mixture of required composition and flow rate was heated and admitted to the membrane cell at atmospheric pressure. The flat-sheet membrane module was placed in a thermal insulation container to keep its temperature constant. All the connections were sealed with double O-rings to assure tightness of insulation. Leakages were tested with soapy liquid at the beginning of experiment. Permeate pressure was maintained below $1 \mathrm{kPa}$ by a vacuum pump and attained a steady state for a certain period of time. The permeated vapor was collected in a cold trap at a given time [39]. An alternate cold trap allowed the permeated vapor to be continuously sampled at all time. Retentate was cooled by a water cooler and collected simultaneously. The permeated and retentate vapor were weighed by a digital analytical balance. Results of the VP experiment were prone to cumulative error arising from vacuum leaks through permeation. The cumulative error was removed by monitoring the stability of permeate pressure. 


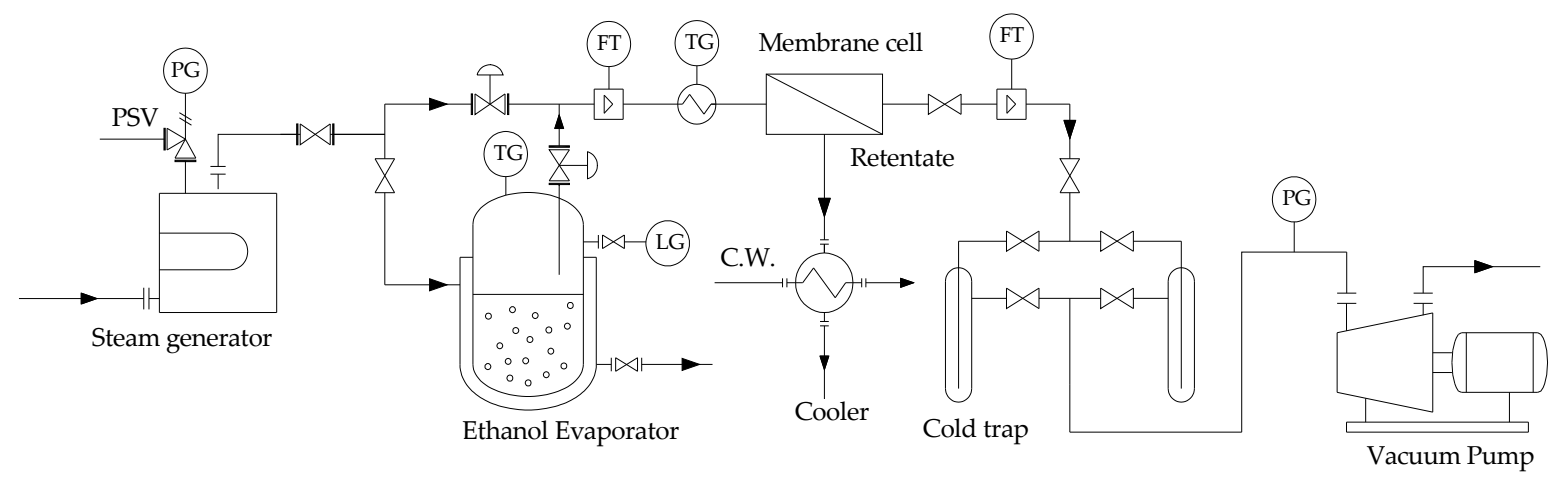

Figure 2. Schematic diagram of the experimental apparatus for VP.

Ethanol concentrations were further analyzed by a high-performance liquid chromatography (HPLC). The samples were diluted to a certain amount, and filtered with $0.45 \mathrm{~nm}$ membranes. Bio-Rad Aminex HPX-87H ion-exchange column and a differential refractive index detector for RID-20A (Shimadzu, Kyoto, Japan) were installed in HPLC. The column temperature was $40{ }^{\circ} \mathrm{C}$, and $0.05 \mathrm{~mol} / \mathrm{L}$ sulfuric acid was prepared as the mobile phase. The flow rate was $0.6 \mathrm{~mL} / \mathrm{min}$. The content was tested by the external standard method.

The effect of ethanol concentration on membrane performance was mainly evaluated in this study. The temperature, differential pressure, and membrane thickness also affect the membrane performance, but in practice, the CSSD employed constant low-pressure steam for extracting the fermented biomass. The feed temperature was usually slightly above the boiling point and fluctuated little from column above the ethanol concentration. Therefore, the effect of temperature and pressure on the membrane performance was not evaluated in this study. The membrane thickness was also constant in the calculation. The feeding steam was saturated with $381 \mathrm{~K}$, and the vacuum degree on the permeate side was maintained at $2 \mathrm{kPa}$ in the experiment. Only the ethanol concentration in the vapor above the CSSD column varied with the stripping steam flow rate, the loading height, and the initial ethanol content in feedstock [36]. Considering the minimum separation factors, tandem PDMS membrane modules might be applied to fit the requirement of hydrophilic membrane feeding requirement. Therefore, ethanol mass fraction range was divided into six groups from $10 \%$ to $60 \%$ in this work. A minimum of three steady-state samples were taken in each group.

\subsection{Evaluation of Membrane Performance}

The performance of membrane is expressed in terms of permeate flux $J$ and separation factor $\alpha$, which are determined as follows [40]:

$$
\begin{gathered}
J=w /(\Delta t \cdot S) \\
\alpha=\left(y_{p e} / x_{p e}\right) /\left(y_{\text {org }} / x_{\text {org }}\right)
\end{gathered}
$$

where $w$ is the sample weight, $S$ is the membrane effective area, and $\Delta t$ is the time interval for sample collection. $y_{p e}$ and $x_{p e}$ are the mass fraction of ethanol and water in the permeate, respectively. $y_{\text {org }}$ and $x_{\text {org }}$ are the mass fraction of ethanol and water in the feed stream, respectively.

The permeate flux $J$ is dependent on the driving force, membrane thickness, and permeability [41]. The intrinsic membrane property of permeability $P_{i}$ is defined as follows:

$$
P_{i}=\frac{J_{i} z}{\Delta f_{i}}
$$

where $J_{i}$ is the molar flux of component $i . z$ is the membrane thickness and $\Delta f_{i}$ the corresponding driving force. In general, the driving force for VP is given by the chemical 
potential gradients of each compound across the membrane. As a result, the driving force can be evaluated based on the pressure difference between the feed and permeate side.

$$
\Delta f_{i}=y_{\text {feed }} p_{\text {feed }}-y_{\text {perm }} p_{\text {perm }}
$$

where $y_{\text {feed }}$ and $y_{\text {perm }}$ are the mole fractions of compound $i$ in the feed and permeate streams, $p_{\text {feed }}$ and $p_{\text {perm }}$ are the feed and permeate pressure $(\mathrm{kPa})$, respectively. $p_{\text {feed }}$ and $p_{\text {perm }}$ remain constant at $101 \mathrm{kPa}$ and $2 \mathrm{kPa}$ across the membrane in the experiment. When the ethanol molecule diffuses alone, the molar flux of ethanol Je can generally be express as:

$$
J_{e}=\frac{P_{e}}{z}\left(y_{\text {feed }} p_{\text {feed }}-y_{\text {perm }} p_{\text {perm }}\right)
$$

Although the PDMS membrane has a strong interfacial affinity for ethanol, the diffusion of water molecules through the membrane cannot be ignored either. The adsorbed water molecules increase the free volume of the polymer. More ethanol molecules pass through the membrane under the driving force and increase the permeation flux of ethanol. In addition to the adsorption and diffusion behavior in the PDMS layer, the PVDF support layer may resist the total ethanol mass transfer on the membrane and be considered in the calculation. Therefore, the total ethanol permeate flux $J_{e t}$ can be expressed as:

$$
J_{\mathrm{et}}=k \Delta f_{e}+J_{e}^{w}-J_{e}^{s}
$$

where $J_{e}^{w}$ is the increase of ethanol flux due to the diffusion of water molecules. $J_{e}^{s}$ is the resistance of the support layer. They can be considered as a constant at low molar ethanol concentration. Therefore, ethanol flux on PDMS behaves nearly linearly as a function of driving force.

The increasing of the free volume also accelerates the diffusion rate of water molecules, which diffuse faster than ethanol molecules due to its smaller kinetic diameter. Therefore, the separation factor decreases. Robeson et al. [42,43] described the trade-off relationship between permeability and selectivity of polymer gas separation membrane, which conforms to the equation:

$$
\alpha_{i j}=\beta_{i j} P_{i}^{-\lambda_{i j}}
$$

where $\lambda_{i j}$ and $\beta_{i j}$ are parameters depending on the gas pair. $\lambda_{i j}=\left(d_{j} / d_{i}\right)^{2}-1, d_{j}$, and $d_{i}$ are the kinetic diameters of the larger and smaller gas, respectively. $\beta_{i j}$ mainly depends on the gas solution. According to Equations (4) and (7), the separation factor can be described as a power function of the driving force:

$$
\alpha_{e w}=\beta_{\mathrm{ew}} P_{e}^{-\lambda_{e w}}=m \beta_{e w w}\left(\frac{1}{\Delta f_{e}}-b\right)^{-\lambda_{e w}}
$$

where $m$ and $b$ are constants. $P_{e}$ is the ethanol permeability, which considers ethanol molecules diffusion alone and the resistance of the support layer.

\subsection{Simulation Methods}

Chemical process simulation program Aspen Plus V8.6 (Bedford, MA, USA) was used to perform steady-state calculation and a portion of equipment costs presented herein. The NRTL-RK thermodynamic model was utilized to determine binary interaction parameters of ethanol and water.

In order to compare two ethanol-enriching methods of rectification and hydrophobic VP membrane, two processes were established separately in simulator. Rectification case, shown schematically in Figure 3a, has been proposed as a method for recovering bioethanol from solid fermentation medium, whereas the phase transition occurred at the top and bottom of the column, making the recovery more energy intensive. To avoid this issue, we have coupled hydrophobic VP membrane units with CSSD column to replace 
rectification column as depicted in Figure 3b, which was called VP case. The unit of solidstate fermentation was identical in both cases, which was not considered in this work. Both cases also included units of dehydration with $\mathrm{NaA}$ zeolite membrane. Changes in CSSD and NaA membrane units caused by different ethanol-enriching sections would be evaluated. All the simulations were conducted at 1 ton fuel ethanol product.

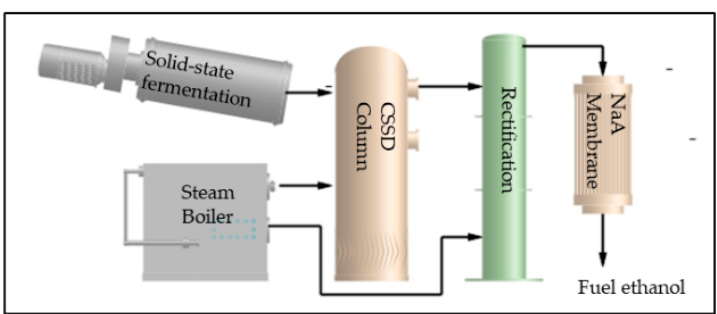

(a)

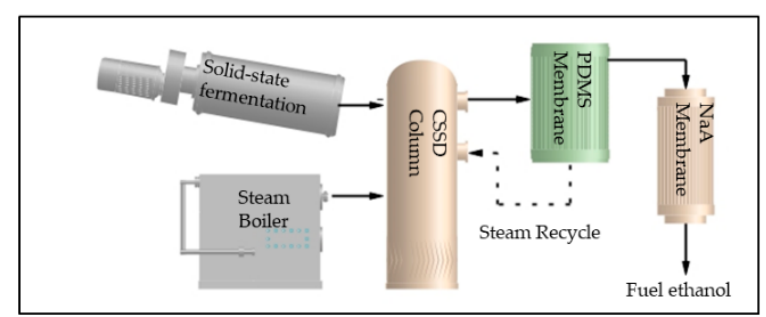

(b)

Figure 3. Schematic diagrams of ethanol-enriching system: (a) rectification case; (b) VP case.

The overhead vapor of CSSD column was considered as the initial flow of the simulation. The literature's values of ethanol concentration and temperature were cited here. A column-restricted calculation module of RadFrac was used for rectification case, and the heat exchangers were simulated by Heater module. VP membrane module calculations were performed in an Excel spreadsheet linked to the workbook built-in the simulator (ASW). The relationship between ethanol flux and separation factor at feeding ethanol concentrations can be obtained by analyzing the experimental data. When the initial flow rate and ethanol concentration were input, through an iterative computation, permeate and retentate ethanol flux in each membrane module was determined as the membrane area. The similar method was used to calculate the NaA zeolite membrane unit. The difference was that the separation factor and permeate flux could cite the existing engineering data, which were provided by Ningbo Sinyuan Membrane Industry in this study.

Flat-sheet membrane modules were used for VP case in experiment and simulation. The pressure drop of the membrane should be considered. The PDMS membrane used in this study is laid over a PVDF support with complicated porosities. The vapor pass through the porous support layer is estimated as Poiseuille flow. The Hagen-Poiseuille equation was applied to determine the pressure drop $(\Delta p)$ across the membrane fiber.

$$
\Delta p=\frac{128 \times \mu \times L \times V_{m}}{\pi \times d^{4}}
$$

where $\mu$ is the kinematic viscosity of the vapor, which was obtained by Aspen property analysis. $L$ is the thickness of the membrane. $V_{m}$ is the feed volume flow rate, and $d$ is the inner pore diameter of the support layer. Calculated pressure losses for flat membrane module were linked to the spreadsheet to estimate the temperatures of permeate and retentate stream.

\section{Results and Discussion}

\subsection{Membrane Performance}

The experimental results are presented in Table 1. Through the above analysis, the correlation between ethanol flux, separation factor and driving force can be fitted with OriginPro 9.0 (Northampton, PA, USA) software based on experimental data. 
Table 1. VP experimental results in different feed ethanol concentration.

\begin{tabular}{ccccc}
\hline $\begin{array}{c}\text { Feed Ethanol } \\
\text { Concentration } \\
\mathbf{( w t} \%)\end{array}$ & $\begin{array}{c}\text { Permeate } \\
\text { Ethanol }\end{array}$ & $\begin{array}{c}\text { Driving Force } \\
\text { Concentration } \\
\mathbf{( w t \% )}\end{array}$ & $\begin{array}{c}\text { Flux of Ethanol } \\
\mathbf{( k P a )}\end{array}$ & $\begin{array}{c}\text { Separation } \\
\left.\mathbf{( k g} / \mathbf{m}^{\mathbf{2}} \mathbf{h}\right) \mathbf{)}\end{array}$ \\
\hline 10 & 28.5 & 3.95 & $3.83 \pm 0.11^{1}$ & $3.59 \pm 0.10^{1}$ \\
20 & 42.7 & 8.58 & $4.46 \pm 0.12^{1}$ & $2.98 \pm 0.08^{1}$ \\
30 & 53.5 & 13.93 & $5.02 \pm 0.16^{1}$ & $2.68 \pm 0.09^{1}$ \\
40 & 61.9 & 20.19 & $5.66 \pm 0.18^{1}$ & $2.44 \pm 0.06^{1}$ \\
50 & 68.8 & 27.57 & $6.06 \pm 0.09^{1}$ & $2.21 \pm 0.11^{1}$ \\
60 & 75.3 & 36.39 & $6.76 \pm 0.11^{1}$ & $2.03 \pm 0.12^{1}$ \\
\hline
\end{tabular}

${ }^{1}$ Result were given as averages of three replicates \pm standard deviation $(p<0.05)$.

The behavior seen in Figure 4 is the correlation between the ethanol flux and the driving force, which is depicted by means of linear fitting. The correlation between the separate factor and the driving force, which is depicted by nonlinear logarithmic fitting method.

$$
\left\{\begin{array}{c}
J_{e t}=0.0846 \Delta f_{e}+3.747 \\
\alpha_{e w}=4.284-0.629 \ln \left(\frac{1}{\Delta f_{e}}-0.911\right)
\end{array}\right.
$$

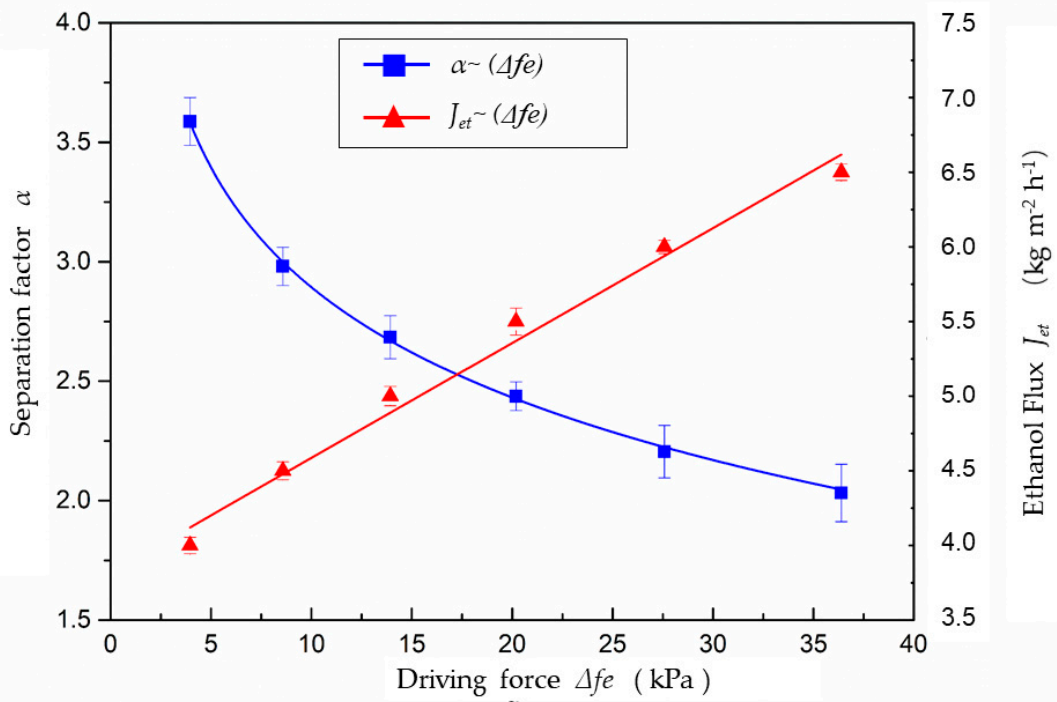

Figure 4. Experimental ethanol flux and separation factors at different driving force.

When the feed concentration is input, the separation factor and ethanol flux can be determined by iteratively calculating the driving force on a spreadsheet. Therefore, the permeate ethanol concentration can be obtained for the simulation. The corresponding membrane area and flow rate of permeate and retentate were also calculated.

\subsection{Processes Analysis}

\subsubsection{Ethanol-Enriching Methods Comparison}

Rectification operation consumes heating steam and cooling water at the same time because the process is dependent on the concentration effect of the vapor-liquid equilibrium. In order to maintain the vapor-liquid circulation in the rectification column, the bottom reboiler and the top condenser need to operate continuously to provide rising vapor and falling liquid stream. The high reflux rate for high ethanol concentration increases the load of reboiler. Moreover, since ethanol-water azeotropes contain $95.4 \mathrm{wt} \%$ ethanol, the column top flow needs to be vaporized and further dehydrated by NaA zeolite membrane or molecular sieve adsorption units. There are at least three phase-transitions occurring 
in the rectification process even if under the vapor feeding condition. When $20^{\circ} \mathrm{C}$ water completely converts to saturate steam, the phase-transition energy is about five times that of heating. Therefore, phase-transition energy accounts for most of energy consumption in bioethanol production.

Vane et al. [31] proposed a vapor-stripping combined VP system to partially replace rectification operation and reduce energy consumption to some extent. However the vapor stripping by steam actually retains the stripping section of the rectification column, while the VP membrane separation only replaces the upper rectifying section. The authors improved the process in subsequent research with dephlegmator to increase the ethanol concentration before VP to reduce the required membrane area. Nevertheless, it still increased unnecessary energy consumption because the main energy consumption of the process comes from the evaporation. The reduction of fuel ethanol cost is more dependent on the low cost of membrane module price than the benefit of energy consumption saving.

The characteristic of VP is that no phase transition occurs across the membrane. As such, the energy consumption is only the pressure drop across the membrane. Therefore, VP has great application potential in energy-efficient fuel ethanol production, especially combined with solid-state fermentation and distillation process. Liquid fermentation broth can be directly input to a rectification column as liquid phase while extracting ethanol from fermented bagasse by steam is a necessary step in solid-state bioethanol production technology. Multiple trays are vertically distributed in CSSD column. The motor drives the scraper to push the fermented bagasse to fall into the lower tray after rotating a circle on the tray. The rising steam counter-current contact with the bagasse to transfer mass and heat. The vapor on each tray flows independently and finally mixes in outlet pipeline at the top of the column [37].

In order to compare two ethanol-enriching methods of rectification and VP, two process flows were simulated based on 1 ton fuel ethanol product as shown in Figure 5 . Both processes include CSSD and VP dehydration with NaA zeolite membrane. The difference in CSSD section is in the different heat recovery modes. The difference of VP dehydration section is because of the different feeding ethanol concentrations. The accumulative separation factor and water flux of $\mathrm{NaA}$ zeolite membrane in series at different feeding ethanol concentration were derived from engineering application data. After dehydration by $\mathrm{NaA}$ zeolite membrane, $1 \mathrm{t}$ of fuel ethanol with $99.5 \mathrm{wt} \%$ concentration was obtained in both cases.

\subsubsection{Rectification Case}

The flowsheet of the rectification case is displayed as Figure 5a. According to the literature values, when the ethanol content in feedstock was $6 \mathrm{wt} \%$, a continuous overhead vapor flow from CSSD column with ethanol concentration of $26.3 \mathrm{wt} \%$ [36]. To overcome the frictional resistance and enable the vapor pressure higher than rectification column pressure, the vapor was reheated to $375 \mathrm{~K}$ and entered the column as the gas phase. The packed column was used in rectification. The theoretical plate number was 75 , and the reflux ratio was 9.2 according to the strict calculation by RadFrac model. In addition, $2.76 \mathrm{t}$ column bottoms could be used as the heat source for preheating fermented sweet sorghum bagasse and partially recover the waste heat. Furthermore, $16.98 \mathrm{t}$ feedstock can be heated to $315 \mathrm{~K}$ by bottoms. The bottoms was recycled as circulating water after treatment. The ethanol concentration of condensate was $94.6 \mathrm{wt} \%$, which was close to the azeotropic point. In addition, $1.06 \mathrm{t}$ distillate was pumped into the reheater to vapor phase and delivered to the NaA zeolite membrane module. Rotary vacuum pump was used to maintain the vacuum degree at $2 \mathrm{kPa}$ at permeation side. The retentate of water-selective membrane was $99.5 \mathrm{wt} \%$ fuel ethanol products. The heat of retentate was recovered to preheat distillate of rectification column at the inlet of the membrane module. The permeate was discharged as sewage. 


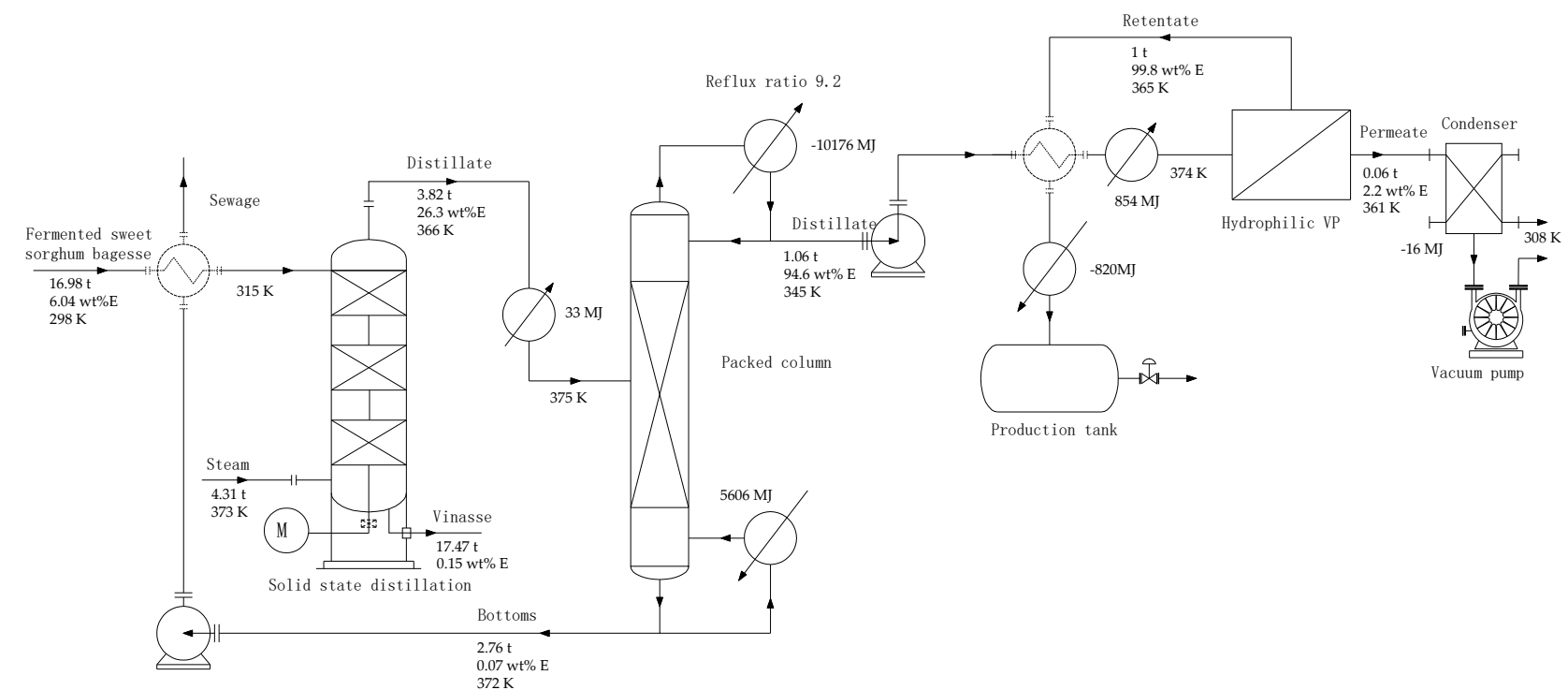

(a)

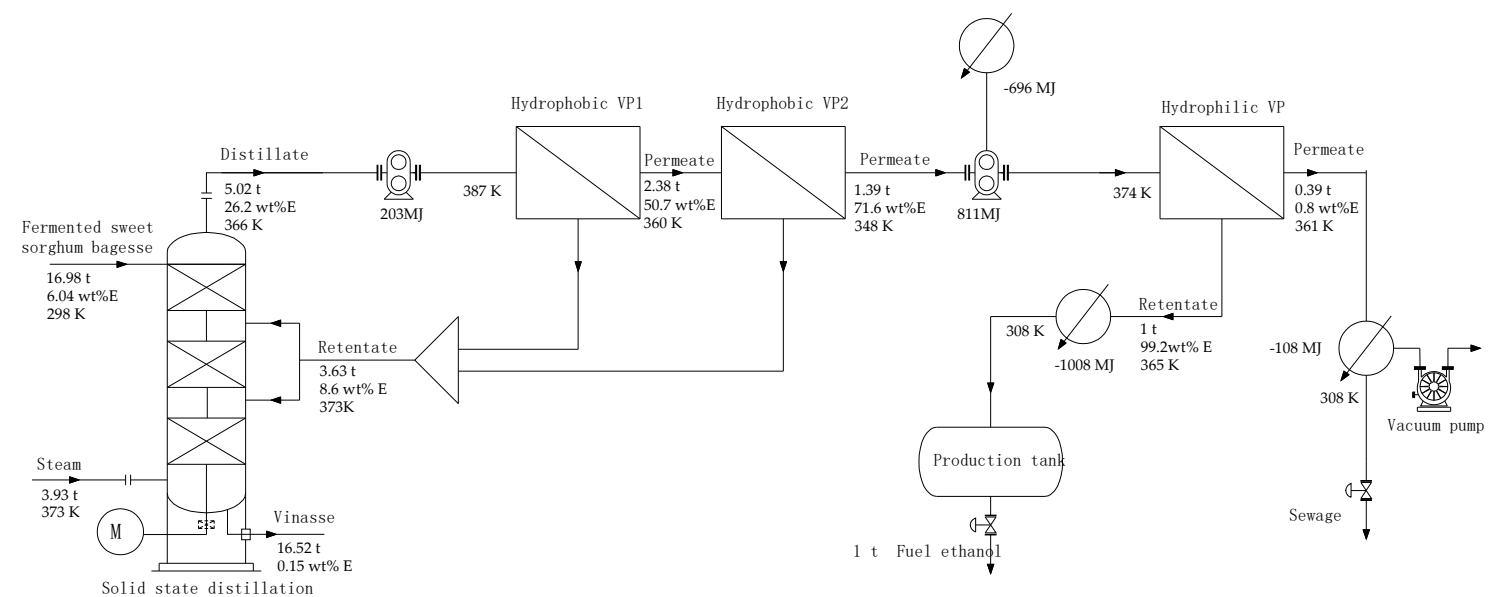

(b)

Figure 5. Flowsheets of ethanol-enriching process base on CSSD (a) rectification case; (b) VP case.

\subsubsection{VP Case}

The process of VP case is shown in Figure 5b. The overhead vapor from the CSSD column was pressurized by a mechanical vapor recompression (MVR) fan and delivered to PDMS/PVDF flat-sheet membrane module at $387 \mathrm{~K}$. The MVR was used to increase the feed pressure appropriately to reduce the vacuum at permeate side ensuring that the driving force on both membrane sides was identified with experimental condition. A tandem of PDMS/PVDF flat-sheet membrane modules was used in series due to the low selectivity of commercial membrane. The ethanol concentration in the outlet stream of the membrane was $71.6 \mathrm{wt} \%$, and the steam mass was $1.39 \mathrm{t}$ according to simulation results. A three-stage vacuum compressor unit was selected to extract permeate stream and maintain the transmembrane driving force. The compressor unit was equipped with interstage cooler to adjust the temperature and to prevent the vapor from being liquefied during compression.

There were still relatively high ethanol content and energy grade in mixed retentate stream of double-hydrophobic-membrane modules, which can be recycled as secondary heat source of CSSD column. The heat released from phase transition of recycled vapor is much higher than temperature differential heat transfer of bottoms in rectification case. Therefore, the primary steam consumption at the bottom of CSSD column is reduced compared with the rectification case. The concentration of the retentate stream was $8.6 \mathrm{wt} \%$, 
which was higher than the feedstock of CSSD column. According to the thermal equilibrium calculation, $2.46 \mathrm{t}$ vapor was condensed to heat the feedstock on the first tray to boiling point. The remaining $0.9 \mathrm{t}$ vapor was mixed with the rising stream, which diluted the concentration of overhead vapor to $26.2 \mathrm{wt} \%$, slightly lower than rectification case. The amount of overhead vapor was increased to $5.02 \mathrm{t}$ due to additional recycled vapor

The concentration of permeate stream across the PDMS/PVDF membrane was $71.6 \mathrm{wt} \%$, which was lower than rectification case. This means that more NaA zeolite membrane area was required to dehydrate the vapor to $99.5 \mathrm{wt} \%$. The VP dehydration process was similar to rectification case, but no heat recycle was designed for retentate of water-selective membrane.

\subsection{Energy Consumption Analysis}

Energy flows for VP case and rectification case are marked in Figure 5. It can be seen that much more heating steam and cooling water were required in the rectification case, while more power to maintain vapor phase conveying was consumed in VP case. To be specific, the rectification column consumed 5606 MJ heat capacity for bottom reboiler and 10,176 MJ cooling capacity for top condenser according to simulation results. In contrast, with the rectification column, there was no phase transition across of the PDMS/PVDF membrane. The energy consumption only works to produce transmembrane driving force, which is provided by MVR on the feed side and the vacuum compressor on the permeate side. The sizes of compressor were achieved on the catalogue as vapor flow rate, suction pressure, and discharge pressure. The work of the compressor was calculated by ASME polytropic model in Aspen simulator. The polytropic and mechanical efficiency was set as 0.75 and 0.95 , respectively. The power consumption of MVR was 203 MJ, and the vacuum compressor was $807 \mathrm{MJ}$. The interstage cooling capacity of compressor is 696 MJ corresponding.

As mentioned above, the two cases applied different energy recovery modes for CSSD column. VP case could recover high-grade retentate vapor as a secondary heating source, which released transition heat to raise the temperature of feedstock to boiling point. However, the rectification column bottoms only preheated the feedstock to $315 \mathrm{~K}$ by temperature differential heat transfer. Therefore, the steam consumption of CSSD column combined with rectification column was $8.8 \%$ more than that of VP process.

The ethanol concentration of vapor feeding to NaA zeolite VP membrane from PDMS/PVDF membrane was $71.6 \mathrm{wt} \%$, which was lower than that of the vapor above the rectification column. In the process of dehydration, the driving force across the $\mathrm{NaA}$ zeolite membrane decreases with the water mole fraction in vapor; therefore, it is necessary to limit the vacuum degree of the permeate side within $2 \mathrm{kPa}$ by a rotary vacuum pump. A vacuum pump is mainly used to extract noncondensable gas from vapor condenser. Assuming that the volume of noncondensable gas accounts for $3 \%$ of the permeate stream, the work of vacuum pump calculated by Equation (11) was $155 \mathrm{MJ}$ in VP case, $129 \mathrm{MJ}$ more than rectification case.

$$
W_{V}=\frac{V_{0} \cdot \Delta p}{\eta_{M}}
$$

where $V_{0}$ indicates the extracted volume of vacuum pump calculated by the ideal gas-state equation. $\eta_{M}$ is the mechanical efficiency, which is assumed as 0.85 in calculation. $\Delta p$ is the pressure difference between outlet and inlet of the vacuum pump. Equation (11) can be also applied to calculate the work of rectification column reboiler and condenser circulating pump. Here, $\Delta p$ represents the head of a centrifugal pump, assuming $25 \mathrm{~m}$ and $V_{0}$ represent the volume flow rate of a centrifugal pump.

Moreover, due to the effect of the overhead condenser in rectification case, the condensate needs to be vaporized again before feeding the membrane module. An additional $854 \mathrm{MJ}$ of heat was accordingly required for vaporization.

Overall, compared with the rectification case, the VP case can reduce $5479 \mathrm{MJ}$ energy input of and $9200 \mathrm{MJ}$ cooling capacity. The energy-saving effect of the hybrid CSSD-VP 
process is significant. However, the hydrophobic VP membrane module consumed more power energy than the rectification column. Considering that the cost of electricity is higher than steam, the two cases are further analyzed economically.

\subsection{Economics Analysis}

Annual fuel ethanol output of the estimated plant was 10,000 t per year and $8760 \mathrm{~h}$ operation. Therefore, the design ethanol production capacity was $1.142 \mathrm{t} / \mathrm{h}$. Since the calculation above was based on 1 ton of fuel ethanol product, the process simulation results in Figure 5 is multiplied by the hour flow coefficient 1.142 in this section.

The above analysis shows that hybrid CSSD-VP process has significant advantages in energy saving, but additional equipment investment and power consumption may increase operating costs. As an emerging technology, hydrophobic membrane is relatively expensive at present. In addition, the cost of vacuum compressors and other equipment for VP membrane module also increased the fixed capital investment.

The costs of purchased equipment for two processes are given in Table 2. All the cost calculations were CNY (7 to 1 against USD) valuation. The equipment price of stainless steel (SS316) packing rectification column and its auxiliaries, including pumps, condenser, and reboiler was taken from cost accounting report of sweet sorghum bioethanol demonstration plant built in 2016. Purchased equipment costs were updated to 2020 prices using a ratio of 1.12, which is determined by comparing the SS316 steel price index for 2020 and base year. The cost of VP membrane module was determined by multiplying the required effective membrane area by the membrane unit price. The service life of the membranes was assumed to be 3 years. The membrane unit price including modules housing and installation framework was assumed without price correction. The PDMS/PVDF membrane area was obtained from simulation results. The NaA zeolite membrane area and unit price were provided by membrane vendor according to simulated feeding vapor flow rates and concentrations. Overall heat transfer coefficients of 850 and $42.5 \mathrm{~W} /\left(\mathrm{m}^{2} \cdot \mathrm{K}\right)$ were assumed for vapor condenser/reboiler and vapor-vapor heat exchangers, respectively. All the heat exchangers were designed as carbon steel shell and stainless-steel fixed U-shaped tubes. Casting materials of single-stage MVR compressor and three-stage Roots vacuum compressor with interstage cooler were carbon steel. The brake horse power (BHP) was converted by hour flow coefficient from the simulation result. The costs of heat exchangers and compressors were obtained from Aspen economic analysis program. The cost options are based on the template of Chinese basis with further price correction as the price of similar existing equipment. The identical equipment in both cases such as CSSD column, product storage tank and sewage tank was not considered in the comparison. It was assumed that the cost of the instrument, piping, installation, maintenance, and operating labor were the same in two cases. In fact, higher piping and installation costs of the rectification column may compensate for the additional instrument and electrical costs of the VP case.

Consumption of utilities such as steam, electricity, and cooling water was calculated on annual as shown in Table 3. The enthalpy value of $0.3 \mathrm{MPa}$ saturated steam is $2725.5 \mathrm{~kJ} / \mathrm{kg}$. The coal price is $550 \mathrm{CNY} / \mathrm{t}$ according to the exit price of steam coal in Qin Port China in November 2020. The cost of coal transportation and coal powder processing was assumed to be $200 \mathrm{CNY} / \mathrm{t}$. The fuel-equivalents boiler efficiency was assumed to be $90 \%$. Considering the costs for boiler water treatment, operating labor and maintenance, the comprehensive price of steam was calculated at $140 \mathrm{CNY} / \mathrm{t}$. The average $2020 \mathrm{China}$ industrial retail price of $0.7 \mathrm{CNY} / \mathrm{kWh}$ for electricity below $1 \mathrm{kV}$ was used in the calculation. The design inlet and outlet temperatures of cooling water were 25 and $33^{\circ} \mathrm{C}$, respectively, and the cooling capacity was $33.4 \mathrm{~kJ} / \mathrm{kg}$. The price of cooling water was calculated as 0.25 $\mathrm{CNY} / \mathrm{t}$ comprehensively, considering the cost of cooling tower, circulating water pump, water treatment, and operating labor. 
Table 2. Purchased equipment costs for rectification case and VP case.

\begin{tabular}{|c|c|c|c|c|c|}
\hline & Equipment & Capacity & Unit Price (CNY) & Amount & Cost (CNY) \\
\hline \multirow{5}{*}{$\begin{array}{l}\text { Rectification } \\
\text { case }\end{array}$} & Rectification column and auxiliaries & & 520,000 & 1.12 & 582,400 \\
\hline & NaA zeolite membrane & & 20,000 & $90 \mathrm{~m}^{2}$ & $1,800,000$ \\
\hline & Vacuum pump & $\mathrm{BHP}=5.4 \mathrm{~kW}$ & 78,000 & 1 & 78,000 \\
\hline & Heat exchangers for dehydration & $\mathrm{A}=21.6 \mathrm{~m}^{2}$ & 152,000 & 1 & 152,000 \\
\hline & Total & & & & $2,612,400$ \\
\hline \multirow{8}{*}{ VP case } & MVR compressor & $\mathrm{BHP}=64 \mathrm{~kW}$ & 372,000 & 1 & 372,000 \\
\hline & Roots vacuum compressor & $\mathrm{BHP}=256 \mathrm{~kW}$ & $1,410,000$ & 1 & $1,410,000$ \\
\hline & Vacuum pump & $\mathrm{BHP}=35 \mathrm{~kW}$ & 165,000 & 1 & 165,000 \\
\hline & PDMS/PVDF membrane & & 7000 & $462 \mathrm{~m}^{2}$ & $3,234,000$ \\
\hline & NaA zeolite membrane & & 20,000 & $140 \mathrm{~m}^{2}$ & $3,240,000$ \\
\hline & Heat exchangers & $\mathrm{A}=12.5 \mathrm{~m}^{2}$ & 106,000 & 1 & 106,000 \\
\hline & Total & & & & $8,527,000$ \\
\hline & Investment balance & & & & $5,914,600$ \\
\hline
\end{tabular}

Table 3. Utility costs for rectification case and VP case.

\begin{tabular}{|c|c|c|c|c|c|}
\hline & Utility & Capacity & Rate & Unit & $\begin{array}{c}\text { Cost } \\
(\mathrm{CNY} / \mathrm{y})\end{array}$ \\
\hline \multirow{4}{*}{$\begin{array}{l}\text { Rectification } \\
\text { case }\end{array}$} & Cooling water & $375.4 \mathrm{t} / \mathrm{h}$ & 0.25 & $\mathrm{CNY} / \mathrm{t}$ & 822,126 \\
\hline & Steam & $8.74 \mathrm{t} / \mathrm{h}$ & 140 & $\mathrm{CNY} / \mathrm{t}$ & $10,718,736$ \\
\hline & Electricity & $46.7 \mathrm{~kW}$ & 0.7 & CNY/kWh & 286,364 \\
\hline & Total & & & & $11,827,226$ \\
\hline \multirow[t]{5}{*}{ VP case } & Cooling water & $59.6 \mathrm{t} / \mathrm{h}$ & 0.25 & $\mathrm{CNY} / \mathrm{t}$ & 130,524 \\
\hline & Steam & $4.49 \mathrm{t} / \mathrm{h}$ & 140 & $\mathrm{CNY} / \mathrm{t}$ & $5,506,536$ \\
\hline & Electricity & $382 \mathrm{~kW}$ & 0.7 & $\mathrm{CNY} / \mathrm{kWh}$ & $2,342,424$ \\
\hline & Total & & & & $7,979,484$ \\
\hline & Utility cost balance & & & & $3,847,742$ \\
\hline
\end{tabular}

As can be seen from Table 3, most of the cost of the rectification case was used for steam and cooling-water consumption; therefore, the cost of steam and cooling water accounts for the vast majority of energy consumption in the ethanol purification process. In contrast, because no phase transition occurred since CSSD column overhead vapor was discharged, the energy consumption of VP process was mainly used to drive compressors to do the volume work on vapor. Therefore, except for the CSSD section, there was no steam consumption in VP case. The majority of energy consumption were power consumed by driving fluid machinery. Although the unit price of electric energy is higher than that of steam, the total energy cost of VP case is much lower than the rectification case.

In general, the capital of VP membrane module is higher than the rectification column with the benefit of the utility cost reduction. To analyze the economy of two cases, the utility cost savings can be treated as the increase of annual operating income. Equation (12) can be used to calculate the discounted payback period (DPP) of additional investment on VP membrane equipment.

$$
\sum_{t=0}^{D P P}(C I-C O)_{t}(1+i)^{t}=0
$$

where $i$ indicates the internal rate of returning, calculated by $12 \%$. CI and $C O$ represent the annual cash inflow and outflow, respectively. The replacement period of VP membrane module was assumed to be 3 years. The other equipment depreciation period was set to 10 years. It can be calculated that the DPP of first-time fixed capital investment was 1.81 years, which is less than hydrophobic membrane 3 years lifetimes. In the next two maintenance periods, the DPP reduce to 1.26 years because only the membrane modules were required to be replaced without compressors and heat exchangers. The results show 
that the capital investment on VP membrane module combined with CSSD to reduce utility cost has better economic benefits.

In this study, commercial PDMS/PVDF membrane was selected, with the characteristic of high permeability but low selectivity. Improving membrane selectivity is the key factor to further reducing membrane area and equipment investment. At present, a number of studies have focused on changing the adsorption properties of polymers to improve the selectivity of steam permeation membranes. Mixing ZSM-5 zeolite with high Si-Al ratio or metal-organic framework (MOF) with PDMS to form mixed matrix membrane was proven to be an effective way to exceed the upper bound of the trade-off relationship between selectivity and permeability [44-46]. Assuming to enhance separation factor average value from 2.6 to 4 at remaining permeate flux, the ethanol concentration at the outlet of hydrophobic membrane could reach $85 \mathrm{wt} \%$. The required membrane area of ethanolselective and water-selective could be reduced by $83 \%$ and $57 \%$, respectively. Provided that the price of hydrophobic membrane per unit area is two-fold of the existing price, the investment capital on the membrane may still be reduced by $63 \%$. That will be more conducive to promote the industrial application of hybrid CSSD-VP ethanol-enriching technology instead of rectification.

\section{Conclusions}

The VP process is predicted to be more energy efficient than rectification for extracting ethanol from solid-state fermented bagasse to produce fuel ethanol than rectification. The technoeconomic analysis indicates that the VP combined CSSD process requires more equipment costs, but the energy and utilities savings could cover the increasing equipment investment. The calculated DPP was 1.81 years less than membrane service lifetime. Further research might explore more selective and cost-effective mixed matrix membrane for VP. The additional investment on VP membrane could be expected to be less than annual utility cost saving.

This study set out to eliminate the phase transition by VP membrane technology to make bioethanol production more energy efficient. The findings reported here shed new light on that the combination of VP and CSSD can further extended the ASSF technology advantage in energy saving and wastewater reducing. It is expected to achieve once phase-transition separation process for bioethanol production, which means that ethanol occurs only once phase transition in the whole conversion process from sweet sorghum to fuel ethanol. Thus, the approach can minimize the energy consumption of bioethanol production and lower the unit price of fuel ethanol.

Author Contributions: Conceptualization, H.L. (Hongshen Li) and S.L.; investigation, H.L. (Hongshen Li), Y.L., and J.N.; methodology, H.L. (Hongshen Li); formal analysis, H.L. (Hongshen Li); validation, Y.L.; writing—original draft preparation, H.L. (Hongshen Li).; writing-review, H.L. (Hongrui Liu) and S.L.; funding acquisition, S.L.; resources, C.S.; project administration, H.L. (Hongrui Liu). All authors have read and agreed to the published version of the manuscript.

Funding: This research was supported by the National Key R\&D Program of China (2016YFE0108500).

Acknowledgments: The authors would like to thank Nanjing Jiusi High-Tech Co. Ltd., China, who provided the commercial membrane for experiment.

Conflicts of Interest: The authors declare no conflict of interest. The funders had no role in the design of the study; in the collection, analyses, or interpretation of data; in the writing of the manuscript, or in the decision to publish the results.

\section{References}

1. Agarwal, A.K. Biofuels (alcohols and biodiesel) applications as fuels for internal combustion engines. Prog. Energy Combust. Sci. 2007, 33, 233-271. [CrossRef]

2. Ramos, M.; Dias, A.P.S.; Puna, J.F.; Gomes, J.; Bordado, J.C. Biodiesel Production Processes and Sustainable Raw Materials. Energies 2019, 12, 4408. [CrossRef] 
3. Balat, M.; Balat, H. Recent trends in global production and utilization of bio-ethanol fuel. Appl. Energy 2009, 86, $2273-2282$. [CrossRef]

4. Chisti, Y. Biodiesel from microalgae. Biotechnol. Adv. 2007, 25, 294-306. [CrossRef]

5. Chhetri, A.B.; Watts, K.C.; Islam, M.R. Waste Cooking Oil as an Alternate Feedstock for Biodiesel Production. Energies 2008, 1, 3-18. [CrossRef]

6. Douvartzides, S.L.; Charisiou, N.D.; Papageridis, K.N.; Goula, M.A. Green Diesel: Biomass Feedstocks, Production Technologies, Catalytic Research, Fuel Properties and Performance in Compression Ignition Internal Combustion Engines. Energies 2019, 12, 809. [CrossRef]

7. Liu, X.; Zhu, F.; Zhang, R.; Zhao, L.; Qi, J. Recent progress on biodiesel production from municipal sewage sludge. Renew. Sust. Energ. Rev. 2021, 135. [CrossRef]

8. Konti, A.; Kekos, D.; Mamma, D. Life Cycle Analysis of the Bioethanol Production from Food Waste-A Review. Energies 2020, 13, 5206. [CrossRef]

9. Kumar, D.; Murthy, G.S. Impact of pretreatment and downstream processing technologies on economics and energy in cellulosic ethanol production. Biotechnol. Biofuels 2011, 4, 19. [CrossRef] [PubMed]

10. Naik, S.N.; Goud, V.V.; Rout, P.K.; Dalai, A.K. Production of first and second generation biofuels: A comprehensive review. Renew. Sust. Energ. Rev. 2010, 14, 578-597. [CrossRef]

11. Zhou, J.Z.; Feng, J.X.; Zhou, Z.X.; Li, S.Z. A Simulation Method Focused on Electric-Heating Distillation of Ethanol in Solid-State Fermented Crushed Straw Material. In Proceedings of the 2017 International Conference on Applied Mathematics, Modelling and Statistics Application; Harish, B.S., Rojas, A.L., Weller, K., Eds.; Atlantis Press: Paris, France, 2017; Volume 141, pp. 107-112.

12. Zabed, H.; Sahu, J.N.; Suely, A.; Boyce, A.N.; Faruq, G. Bioethanol production from renewable sources: Current perspectives and technological progress. Renew. Sust. Energ. Rev. 2017, 71, 475-501. [CrossRef]

13. Singh, A.; Rangaiah, G.P. Development and optimization of a novel process of double-effect distillation with vapor recompression for bioethanol recovery and vapor permeation for bioethanol dehydration. J. Chem. Technol. Biotechnol. 2019, 94, 1041-1056. [CrossRef]

14. Torres Cantero, C.A.; Lopez Lopez, G.; Alvarado, V.M.; Escobar Jimenez, R.F.; Rumbo Morales, J.Y.; Sanchez Coronado, E.M Control Structures Evaluation for a Salt Extractive Distillation Pilot Plant: Application to Bio-Ethanol Dehydration. Energies 2017, 10, 1276. [CrossRef]

15. Mei, X.; Liu, R.; Cao, W. Energy consumption analysis on pilot-scale plant of fuel ethanol production from sweet sorghum stalk by solid state fermentation. Trans. Chin. Soc. Agric. Eng. 2012, 28, 194-198.

16. Tian, Y.; Li, S.; Zhao, L.; Meng, H.; Huo, L. Life Cycle Assessment on Fuel Ethanol Producing from Sweet Sorghum Stalks. Trans. Chin. Soc. Agric. Mach. 2011, 42, 132-137.

17. Gozan, M.; Setiawan, M.S.; Lischer, K. Purification Simulation With Vapor Permeation and Distillation-Adsorption In Bioethanol Plant. Makara J. Technol. 2017, 21, 43-48. [CrossRef]

18. Wang, Y.C.; Teng, M.Y.; Lee, K.R.; Lai, J.Y. Comparison between the pervaporation and vapor permeation performances of polycarbonate membranes. Eur. Polym. J. 2005, 41, 1667-1673. [CrossRef]

19. Hietaharju, J.; Kangas, J.; Tanskanen, J. Analysis of the permeation behavior of ethanol/water mixtures through a polydimethylsiloxane (PDMS) membrane in pervaporation and vapor permeation conditions. Sep. Purif. Technol. 2019, 227, 13. [CrossRef]

20. Gaykawad, S.S.; van der Wielen, L.A.M.; Straathof, A.J.J. Effects of yeast-originating polymeric compounds on ethanol pervaporation. Bioresour. Technol. 2012, 116, 9-14. [CrossRef]

21. Sander, U.; Janssen, H. Industrial application of vapor permeation. J. Membr. Sci. 1991, 61, 113-129. [CrossRef]

22. Vane, L.M. Review: Membrane materials for the removal of water from industrial solvents by pervaporation and vapor permeation. J. Chem. Technol. Biotechnol. 2019, 94, 343-365. [CrossRef]

23. Khalid, A.; Aslam, M.; Qyyum, M.A.; Faisal, A.; Khan, A.L.; Ahmed, F.; Lee, M.; Kim, J.; Jang, N.; Chang, I.S.; et al. Membrane separation processes for dehydration of bioethanol from fermentation broths: Recent developments, challenges, and prospects. Renew. Sustain. Energ. Rev. 2019, 105, 427-443. [CrossRef]

24. Li, H.; Guo, C.; Guo, H.; Yu, C.; Li, X.; Gao, X. Methodology for design of vapor permeation membrane-assisted distillation processes for aqueous azeotrope dehydration. J. Membr. Sci. 2019, 579, 318-328. [CrossRef]

25. Makertihartha, I.G.B.N.; Dharmawijaya, P.T.; Wenten, I.G. Recent Advances on Bioethanol Dehydration using Zeolite Membrane. In International Conference on Energy Sciences; Waris, A., Shin, B., Kondo, M., Buys, Y.F., Irwanto, D., Pramuditya, S., Eds.; IOP: London, UK, 2017; Volume 877.

26. Sun, W.; Jia, W.; Xia, C.J.; Zhang, W.D.; Ren, Z.Q. Study of in situ ethanol recovery via vapor permeation from fermentation. J. Membr. Sci. 2017, 530, 192-200. [CrossRef]

27. Orozco-Gonzalez, N.; Bustamantea, F.; Acosta-Cardenas, A. Experimental assessment of the integration of in situ removal of ethanol by pervaporation with a simultaneous saccharification-fermentation process. J. Chem. Technol. Biotechnol. 2016, 91, 3011-3017. [CrossRef]

28. Sun, D.; Li, B.B.; Xu, Z.L. Pervaporation of ethanol/water mixture by organophilic nano-silica filled PDMS composite membranes. Desalination 2013, 322, 159-166. [CrossRef]

29. Lipnizki, F. Membrane process opportunities and challenges in the bioethanol industry. Desalination 2010, 250, 1067-1069. [CrossRef] 
30. Gaykawad, S.S.; Rutze, D.N.; van der Wielen, L.A.M.; Straathof, A.J.J. Vapour permeation for ethanol recovery from fermentation off-gas. Biochem. Eng. J. 2017, 124, 54-63. [CrossRef]

31. Vane, L.M.; Alvarez, F.R. Membrane-assisted vapor stripping: Energy efficient hybrid distillation-vapor permeation process for alcohol-water separation. J. Chem. Technol. Biotechnol. 2008, 83, 1275-1287. [CrossRef]

32. Vane, L.M.; Alvarez, F.R.; Huang, Y.; Baker, R.W. Experimental validation of hybrid distillation-vapor permeation process for energy efficient ethanol-water separation. J. Chem. Technol. Biotechnol. 2010, 85, 502-511.

33. Vane, L.M.; Alvarez, F.R. Effect of membrane and process characteristics on cost and energy usage for separating alcohol-water mixtures using a hybrid vapor stripping-vapor permeation process. J. Chem. Technol. Biotechnol. 2015, 90, 1380-1390. [CrossRef]

34. Li, S.Z.; Li, G.M.; Zhang, L.; Zhou, Z.X.; Han, B.; Hou, W.H.; Wang, J.B.; Li, T.C. A demonstration study of ethanol production from sweet sorghum stems with advanced solid state fermentation technology. Appl. Energy 2013, 102, 260-265. [CrossRef]

35. Appiah-Nkansah, N.B.; Li, J.; Rooney, W.; Wang, D.H. A review of sweet sorghum as a viable renewable bioenergy crop and its techno-economic analysis. Renew. Energy 2019, 143, 1121-1132. [CrossRef]

36. Li, H.S.; Li, S.Z. Optimization of Continuous Solid-State Distillation Process for Cost-Effective Bioethanol Production. Energies 2020, 13, 854. [CrossRef]

37. Li, S.; Li, G. Continuous solid-state separation device and process for producing fuel ethanol. US Patent 10239806, 26 March 2019.

38. Yang, W.; Zhou, H.; Zong, C.; Li, Y.; Jin, W. Study on membrane performance in vapor permeation of VOC/N-2 mixtures via modified constant volume/variable pressure method. Sep. Purif. Technol. 2018, 200, 273-283. [CrossRef]

39. Brenninkmeijer, C.A.M. Automated variable temperature liquid nitrogen cold trap. Anal. Chem. 1982, 54, 2622-2623. [CrossRef]

40. Huang, R.Y.M. Pervaporation Membrane Separation Processes; Elsevier: Amsterdam, The Netherlands, 1991.

41. Sommer, S.; Melin, T. Influence of operation parameters on the separation of mixtures by pervaporation and vapor permeation with inorganic membranes. Part 1: Dehydration of solvents. Chem. Eng. Sci. 2005, 60, 4509-4523. [CrossRef]

42. Robeson, L.M. Correlation of separation factor versue permeability for polymetric membrane. J. Membr. Sci. 1991, 62, 165-185. [CrossRef]

43. Park, H.B.; Kamcev, J.; Robeson, L.M.; Elimelech, M.; Freeman, B.D. Maximizing the right stuff: The trade-off between membrane permeability and selectivity. Science 2017, 356, 10. [CrossRef] [PubMed]

44. Liu, J.; Chen, J.X.; Zhan, X.; Fang, M.Q.; Wang, T.; Li, J.D. Preparation and characterization of ZSM-5/PDMS hybrid pervaporation membranes: Laboratory results and pilot-scale performance. Sep. Purif. Technol. 2015, 150, 257-267. [CrossRef]

45. Zhan, X.; Lu, J.; Xu, H.; Liu, J.; Liu, X.; Cao, X.; Li, J. Enhanced pervaporation performance of PDMS membranes based on nano-sized Octa (trimethoxysilyl)ethyl -POSS as macro-crosslinker. Appl. Surf. Sci. 2019, 473, 785-798. [CrossRef]

46. Rangnekar, N.; Mittal, N.; Elyassi, B.; Caro, J.; Tsapatsis, M. Zeolite membranes-A review and comparison with MOFs. Chem. Soc. Rev. 2015, 44, 7128-7154. [CrossRef] [PubMed] 